\title{
Narrow, powerful, and public: The influence of brand breadth in the luxury market
}

\author{
Youngseon Kim, Ph.D. \\ Central Connecticut State University \\ Nikki Wingate, Ph.D. \\ University of Bridgeport
}

\section{Abstract}

Although the current literature in brand extensions is replete with studies in both line and category extensions, the effect of brand breadth (magnitude of the category extensions) is still yet to be thoroughly examined. Few researchers have focused on brand breadth, to suggest when to choose a narrow (vs. broad) brand extension strategy. Accordingly, no theoretical explanations support the co-existence of both narrow brands (i.e., brands with extensions in similar categories) and broad brands (i.e., brands with extensions in dissimilar categories), particularly in the luxury market. In order to provide guidelines for luxury marketers to enhance overall brand equity, we investigate conditions under which narrow brands are more strongly preferred to broad brands in the luxury market, using a total of 389 respondents recruited via Amazon M-turks and 230 university volunteers in four experiments. Findings demonstrate that narrow brands are liked more than broad brands only with consumers who feel powerful and desire status, and especially when the consumption occurs in public. Highlighting the importance of brand breadth, the current research contributes to the literatures in brand extensions and luxury branding by supplying theoretical guidelines to formulate successful brand extension strategies for luxury marketers.

\section{Research Background}

Managing Horizontal Brand Extension Strategy: Narrow vs. Broad Brands

The extant literature on brand extension has emphasized the fit between the parent brand and its extension(s) as a key factor for successfully managing brand extensions (e.g., Ahluwalia, 2008; Czellar 2003; Hem et al., 2003; Völckner and Sattler, 2007). Horizontal extensions represent brand extensions into product categories different from the parent brand's original product category (Aaker and Keller, 1990). Consistent with the concepts of brand breadth (Boush and Loken, 1991) and broad versus narrow brands (Meyvis and Janiszewski, 2004), we define a broad luxury brand and a narrow luxury brand as follows.

A broad luxury brand has a diverse set of extensions either similar to the parent brand's original product category or dissimilar to the parent brand's original product category, beyond the boundaries of traditional luxury sectors. Examples of such broad luxury brands that started in a high-end designer clothing category and later extended to handbags, jewelry, fashion accessories, furniture, home goods, hotels, and restaurants include Armani, Bulgari, Ralph Lauren, and Versace.

In contrast, a narrow luxury brand has extensions similar to the parent brand's original product category, with extensions concentrated in related industries. These narrow luxury brands, such as Hermès, Louis Vuitton, and Gucci, originally started as luxury leather goods provider and kept the extensions within one industry of fashion accessories, covering handbags, jewelry, clothing, fashion accessories, cosmetics, and watches.

In sum, narrow luxury brands extend within traditional luxury product categories (e.g., fashion, clothing, leather goods and accessories, fragrances, watches, and jewelry), whereas broad luxury brands extend broadly to nontraditional luxury segments of lifestyle and hospitality (furniture, travel, hotels, etc.) in addition to the traditional luxury product categories (Albrecht et al., 2013).

\section{Research Questions and Hypotheses}

H1: Consumers will like narrow luxury brands more than broad luxury brands.

H2: Consumers with a powerful mindset will prefer narrow luxury brands to broad luxury brands more than consumers with a powerless mindset.

H3: The effect of the powerful mindset on consumers' preference for narrow (vs. broad) luxury brands will be mediated by the perception that acquiring narrow (vs. broad) luxury brands will help them express a higher status.

H4: The preference of narrow (vs. broad) luxury brands by consumers in powerful mindset will be more pronounced in public (vs. private) consumption context.

\section{Research Methodology}

Experimental methodology via four studies involving a total of 389 respondents recruited via Amazon M-turks and 230 university volunteers.

\section{Research Stimuli}

A company uses its established brand name to introduce a new product category. The new category to which a brand is extended can be related or unrelated to its original product category. This marketing initiative is called brand extension. Many luxury brands adopt the brand extension strategy as well. One type of brand exterions adopted by luxury brands is natons bre Con only similar wr related to is ong al product category.

Please imagine a luxury brand whose original product category is a designer's fashion clothing. It has decided to take a narrow brand extension strategy Therefore, it offers bags, shoes, watches, jewelry, sunglasses, and fashion accessories under the same brand name. Its extension range is relatively small and its brand name is only found in a certain number of product categories.

What do you think about a luxury brand with narrow extensions?

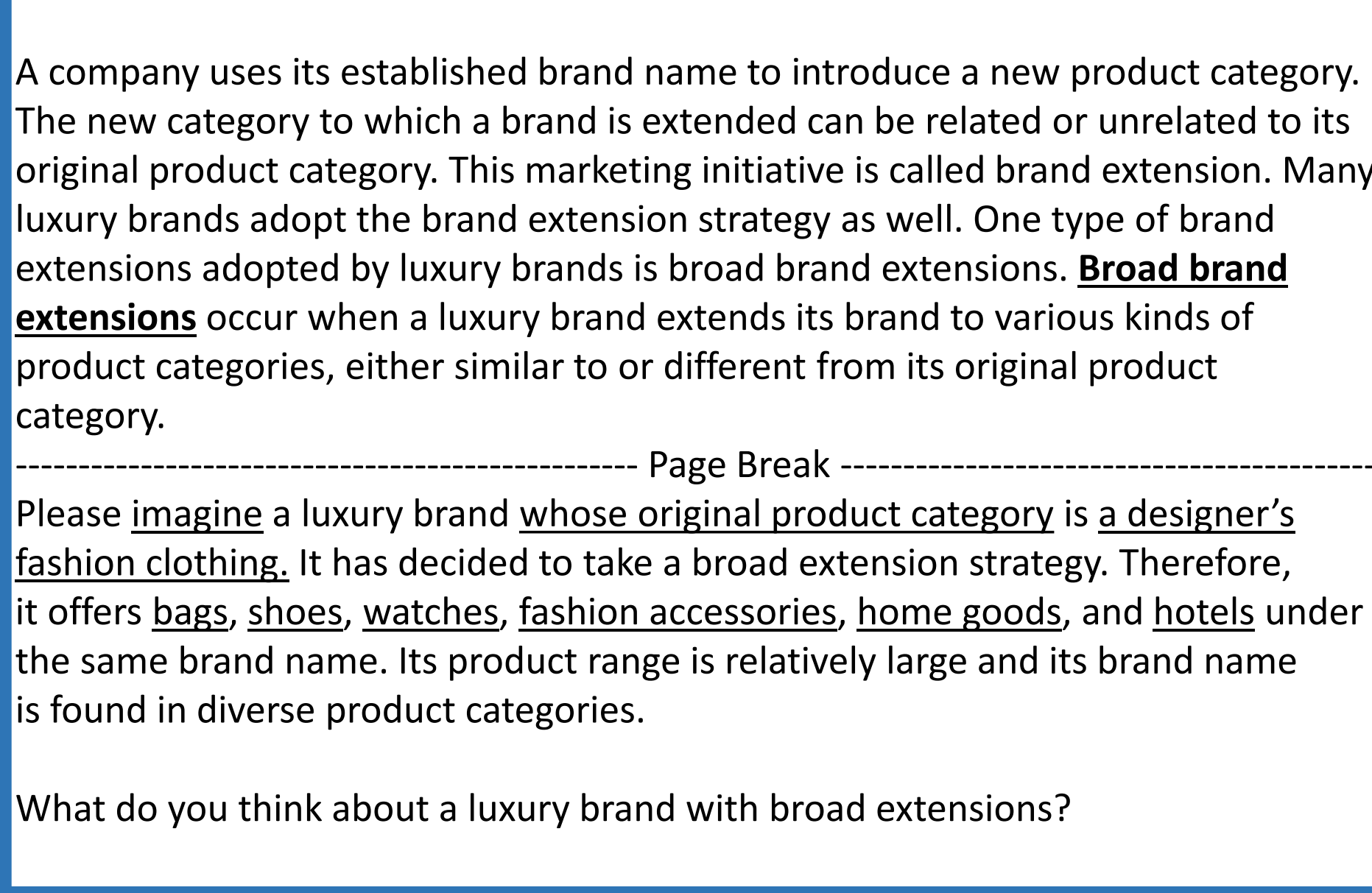

Research Findings

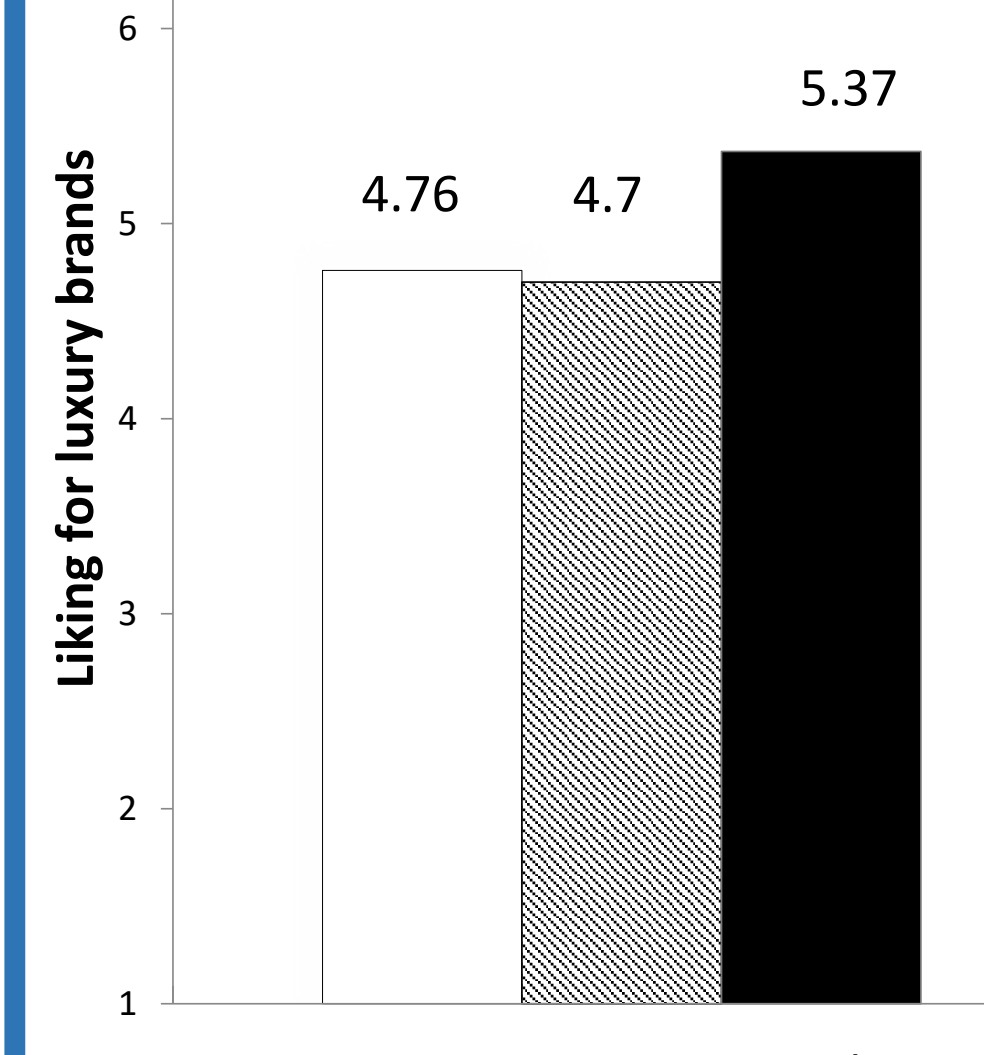

Narrow Luxury Brand

$\square$ Control $\mathbb{Q}$ Powerless - Powerfu

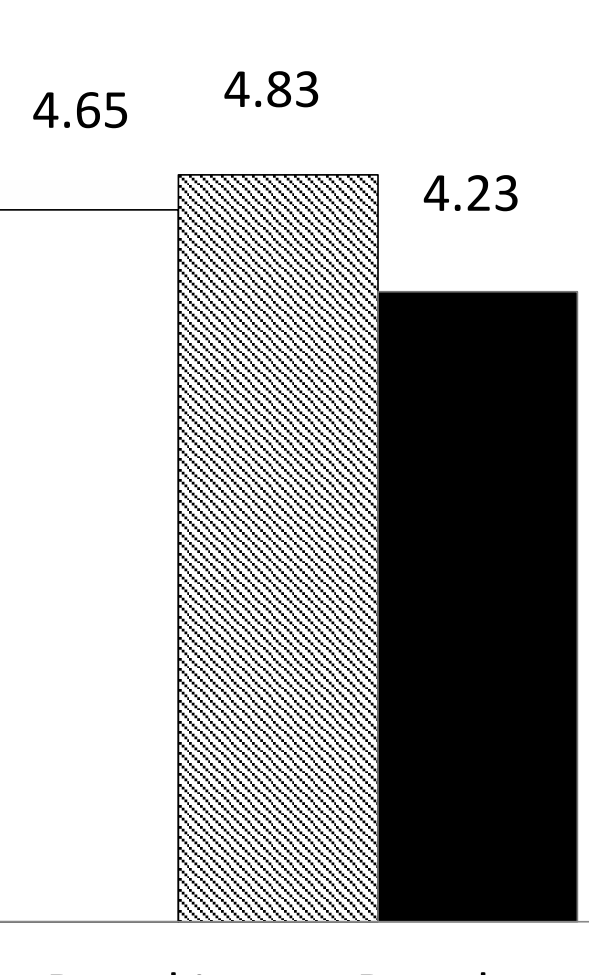

Broad Luxury Brands

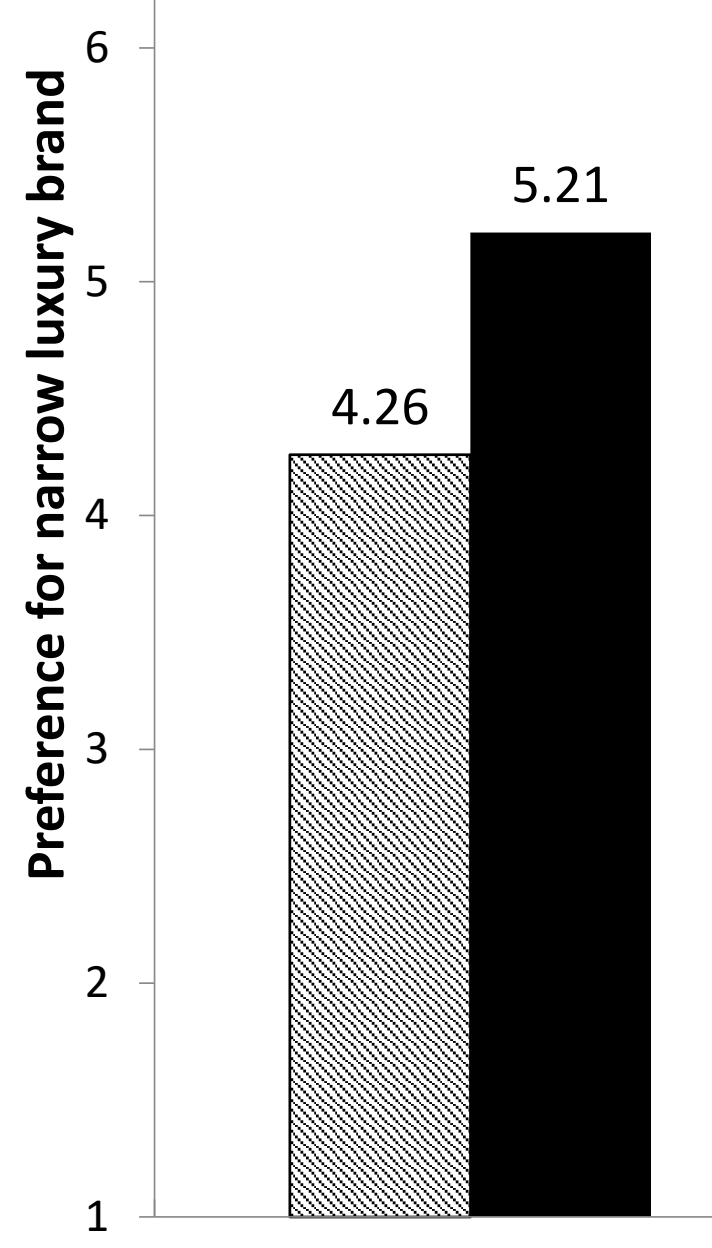

Public consumption

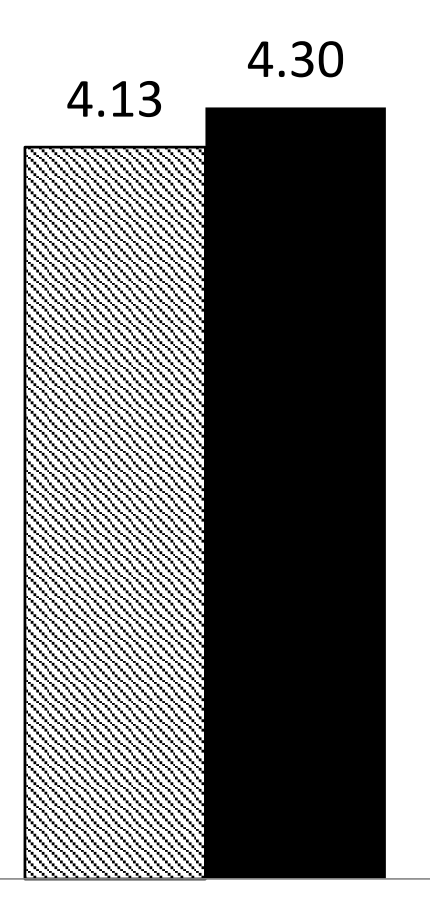

Private consumption
Broad Luxury Brand

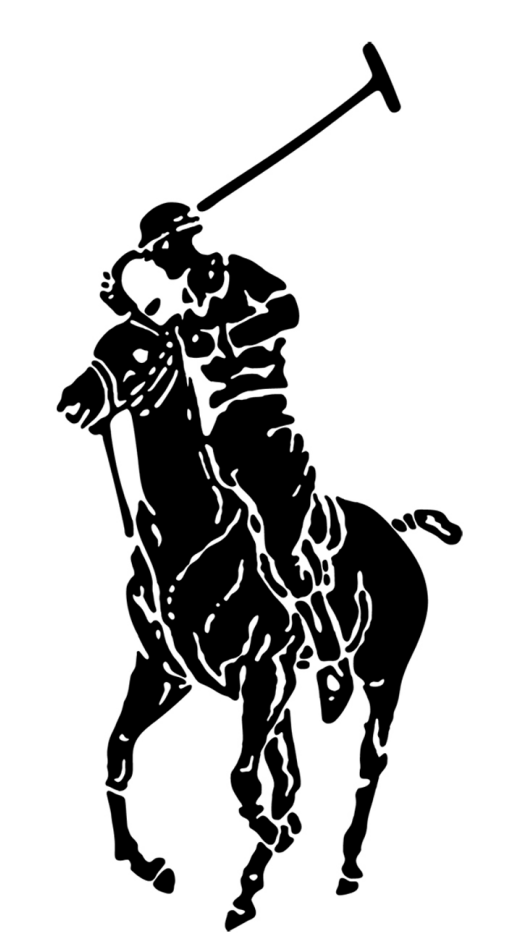

R A L P H vs.

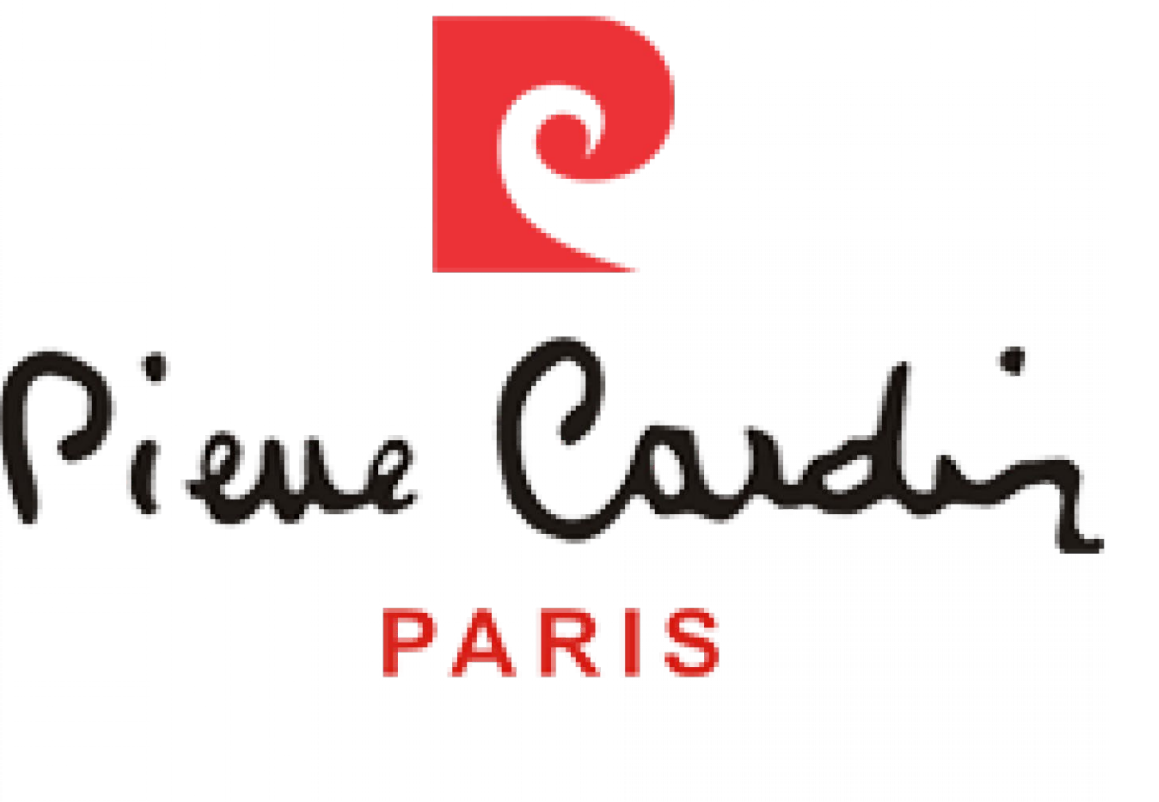

PARIS
Narrow Luxury Brand 